\title{
Health Seeking Behavior of Health Disorders of Men among Government Servants in Kuantan: Prevalence Study towards a Healthy Ummah
}

\author{
Syamsul Ahmad Arifin ${ }^{1,2}$, Afzan Mat Yusuf ${ }^{1,2}$, Raja Ili Nabilah', Lokman Md Isa, ${ }^{1,2}$ \\ ${ }^{1}$ Department of Basic Medical Sciences, Kulliyyah of Nursing, Islamic University Malaysia Kuantan \\ 2IIUM Human Cellular and Molecular Biology Research Cluster (iMolec), International Islamic University \\ Malaysia Kuantan
}

\begin{abstract}
As age advances most of body system will follow a process of deterioration too and the same goes for reproductive health. There is a gap between the prevalence of reproductive health disorders and rates of treatment. This gap among middle aged and older men is still wide compared to other chronic disease. In Islam, seeking medical treatment for the cure of diseases is part of the Prophet's tradition and the Prophet (PBUH.) said in the Hadith the following: "For every disease there is a medicine, and if that medicine is applied to the disease, he will recover by Allah's Leave." Therefore the aim of this study is to identify a health seeking behaviour among men in for men's health $(\mathrm{MH})$ disorders in Kuantan. A cross sectional study was conducted among 157 respondents from four governments agencies and the data was collected using self-administered questionnaire modified from a valid and reliable measure. The results showed that $68.2 \%$ of the respondents $(n=107)$ have high attitude in seeking for health regarding men's health while for the rest of the respondents $(n=50,31.8 \%)$ have low attitude in seeking for MH. Men from the Service factor are perceived the highest compared the other two factors which are cultural and economic factors. This study showed that $\mathrm{MH}$ that includes reproductive disorders has always been taken lightly by the community itself. A Lack of awareness regarding $M E$ issue causes men to ignore the importance of health screening. This should be improved in order to produce a healthy community for better Ummah since good heredity begins with good ME.
\end{abstract}

KEYWORDS: Men's health, attitude, Islamic perspective, reproductive disorders, human behaviour

\section{INTRODUCTION}

Male reproductive disorders can be classified as complex as it includes both the reproductive and urinary systems. Regarding sexual aspect, the aging in men will bring a deterioration of their sexual response and function. ${ }^{1}$ Normally, men above the age of 40 tend to have slower response and the genital organ becomes less sensitive. Their sexual activity may still be pleasurable even though the sexual excitement and orgasm may have lessened. Erectile dysfunction is known as the most common disorder among male sexual health problems ${ }^{2}$. The other common reproductive disorder is a Lower Urinary Tract Symptoms (LUTS). Japan had the highest prevalence of LUTS among men age 40 and above which is $56 \%$, compared to Korea which is $16.2 \% .^{3}$

Corresponding author:

Muhammad Lokman Md Isa

Department of Basic Medical Sciences,

Kulliyyah of Nursing

IIUM Human Cellular and Molecular Biology Cluster

(iMoleC),

International Islamic University Malaysia

Jalan Sultan Ahmad Shah, 25200 Kuantan, Pahang

Telephone: +6012 9645581

Email: lokman@iium.edu.my
Socio-demographic factors such as age, marital status, race, occupation and level of education can be associated with health seeking behaviour. In a logistic regression model that includes age, occupation, and education, only the age remains significant for health seeking behavior. ${ }^{4}$ Men seek help related to health less frequently compared with women, which lead to higher numbers of early mortality among men aged 50 and above. ${ }^{5}$ There is still a wide gap between the prevalence of reproductive health disorders and rates of treatment seeking behaviour among middle aged and older men, and still low compared to other chronic disease. ${ }^{1,6}$

Three factors affecting health-seeking behavior among men are service factors, socio-economic factors and culture. Men reluctant to seek for medical treatment is may be due to the service provided by the healthcare providers. One of the reason is that the services provided are generally not oriented to the needs of men or 'not men friendly". Courtenay (2003) reported that socio economic factor show strong association with health seeking pattern in men. ${ }^{7}$ Financialstatus is one of the major factors that causes reduction in the number of health seeking treatment. Lack of money can be 
a draw back in seeking medical treatment. Culture was also one of the barriers in health seeking behavior (Mansfield et al.2003). ${ }^{8}$ Men are seen as the dominant and masculine, and added with stoicism and restraining of emotion are factors associated with masculine gender. At the same time men are also influenced by the cultural stereotypes to ignore screening and preventive measures and delaying seeking help for medical treatment. ${ }^{9}$ In Islam, seeking medical treatment for the cure of diseases is part of the prophet's tradition and in a Hadith that the Prophet (PBUH said the following: "For every disease there is a medicine, and if that medicine is applied to the disease, he will recover by Allah's Leave."

Therefore the aims of this study are to find association between demographic data with the attitudes of men in seeking treatment and finding association between demographic data and factors affecting health seeking behavior in three selected areas in Kuantan.

\section{MATERIAL AND METHODS}

\section{Study Design}

A cross sectional study with convenience sampling was conducted and the data was collected using self -administered questionnaire modified from a valid and reliable measure. The demographic data in this study includes age, marital status, and income. The subject of this study is anyone that works in the four government agencies which are JPAM, KASTAM, JPJ and Jabatan Bomba dan Keselamatan.

\section{Sample Selection}

Samples were selected from men who aged 30 and above that work at the said government agencies. The sample size that is recommended for the purpose of this study was 210 which have been calculated using Raosoft.com software. The sample population was taken from the human resource of each government agencies for the numbers of men who is working in specific agencies.

\section{Study Instruments}

Data was collected through survey with the questionnaire regarding health seeking behavior among government servants in Kuantan. The questionnaires were distributed among the males population of the said government agencies in Kuantan where many males worked. The researcher gave a brief explanation on the title of the study, the objectives and the consent procedure. The consent form was given to them and they signed willingly. After the data were collected it was verified in order to reject any invalid questionnaire. Invalid questionnaire meant those questionnaires which were incomplete, and the age of the respondents was less than 30 years old.

This was a close ended modified questionnaire that consists of few parts which are: Part 1: about demographic data that include age, marital status and income. Part 2 is focusing on attitude of men in health seeking behavior regarding men's health. Part 3 of the questionnaire is covering the influential factors in men who do not seek for treatment. The independent variables in this study are the demographic data which are age, marital status, and income. While the dependent variable in this study is the attitude of the men in health seeking behavior regarding men's health disorders, and the factors affecting health seeking behavior in $\mathrm{MH}$ disorders which are service, cultural and economic.

A pilot study was done among 20 volunteers who were given the modified questionnaire to be tested (self-administered). Any unclear questions or questions that cause confusion to the participants were adjusted to a satisfactory level. Approvals of this study were from the Kulliyyah of Nursing and International Islamic University (IIUM) ethics Committee and the Public Relation and Community, Kuantan Municipal Counsel.

\section{Statistical Analysis}

The collected data were analyzed by using Statistical Package for Social Sciences (SPSS) version 18.0. Descriptive statistics (frequency, mean, median and standard deviation) were used to describe socio-demographic data and also dependent variables of the study. One way Analysis of Variance (ANOVA) test was used in order to find an association between the demographic data (age and income) with the attitudes of men in men's health seeking behavior while independent T-test was used to find an association between demographic data (marital status) with the attitudes of men in men's health seeking behavior. Pearson correlation was used to find correlation between factors (service, cultural, economic) affecting men's health seeking behavior with attitudes of men in seeking help regarding men's health.

\section{RESULTS}

Of the 210 respondents, only 157 respondents participated in answering the questionnaire. The other $25 \%$ did not respond to the questionnaire and some of them did not return the questionnaires. Table 1 shows the demographic data of respondents. Age was grouped into four classes, those who aged 30-40, 41-50, 51-60 and lastly those above 60 years. In this study, most of the participants were from those who aged $30-40$ (51\%), followed by those from $41-50(26.1 \%)$, and then $51-60(22.3 \%)$ and lastly aged 60 and above (0.6\%). During the study, 126 of the respondents were married $(80.3 \%)$ while the rest were single $(n=31,19.7 \%)$. For income data, it was also classified into four groups, those who earned less than RM 1000, those between RM 1001-RM 3000, those RM 3001-RM 5000 and those more than RM 5000. From the Table 1 , it is seen that most of the respondents earned between RM 1001-RM 3000 ( $n=$ $81,51.6 \%$ ). While 40 respondents earned more than RM 3001 (29.3\%), and other 30 respondents earned less than RM 1000 (19.1\%). 
Table 1

Frequency and Percentage Demographic Data of the samples in this study

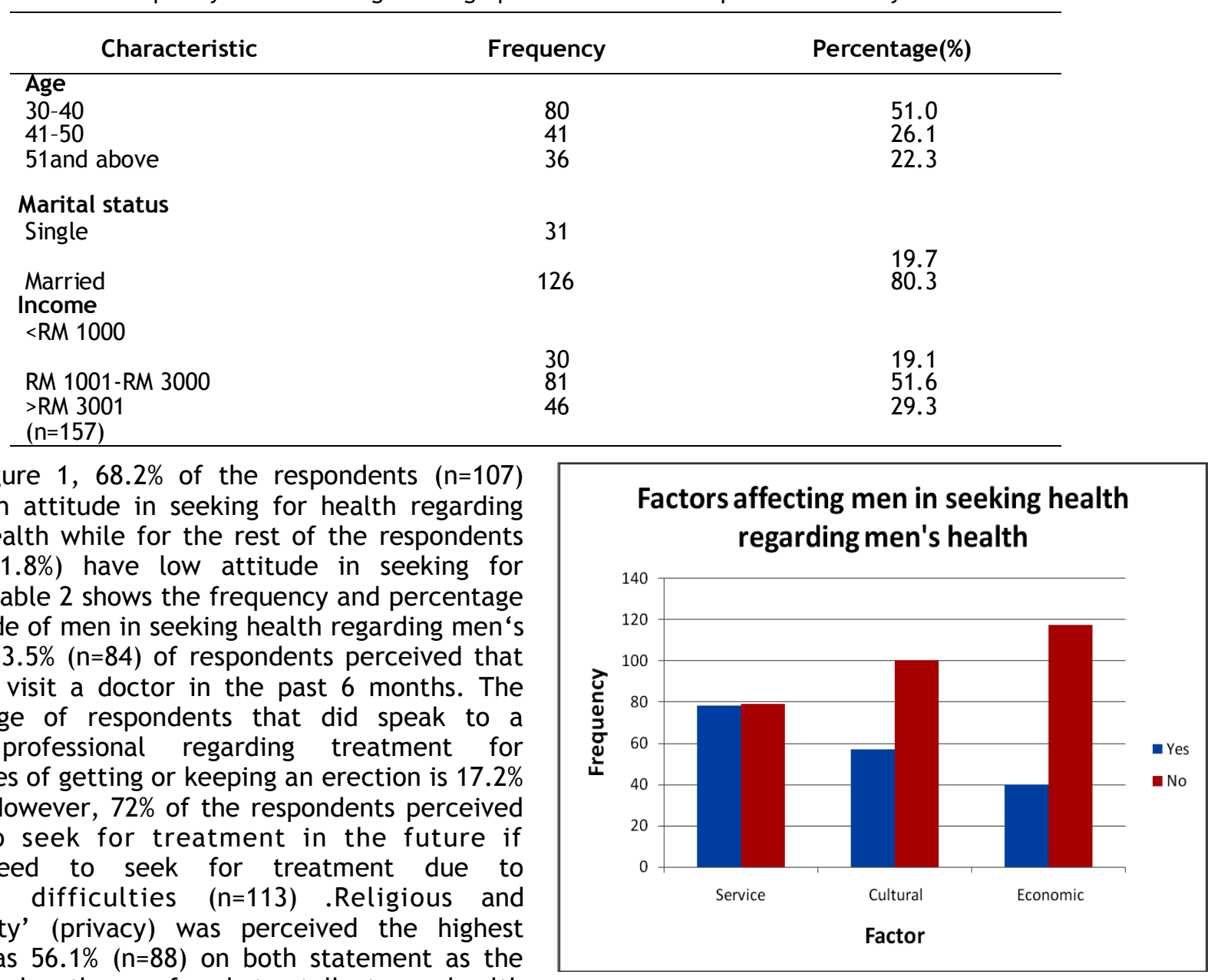

From Figure 1, 68.2\% of the respondents $(n=107)$ have high attitude in seeking for health regarding men's health while for the rest of the respondents $(n=50,31.8 \%)$ have low attitude in seeking for health. Table 2 shows the frequency and percentage of attitude of men in seeking health regarding men's health. $53.5 \%(n=84)$ of respondents perceived that they did visit a doctor in the past 6 months. The percentage of respondents that did speak to a health professional regarding treatment for difficulties of getting or keeping an erection is $17.2 \%$ $(n=27)$. However, $72 \%$ of the respondents perceived "yes" to seek for treatment in the future if they need to seek for treatment due to erection difficulties $(n=113)$.Religious and 'sensitivity' (privacy) was perceived the highest which was $56.1 \%(n=88)$ on both statement as the reasons why they refused to talk to a health professional about erectile problems. Among 157 respondents, only $17(10.8 \%)$ respondents were happy to spend the rest of their life with their current prostate health as it was. While the rest of the respondents $89.2 \%, n=140$ were not happy with their currents prostate health. Figure 2 shows that service factor perceived the highest compared to the other two factors which were cultural and economic factors. $50.3 \% \quad(n=78)$ of respondents perceived "yes" for the service factor followed by cultural factor $(36.3 \%, \mathrm{n}=57)$ and economic factor $(25.5 \%, n=40)$.

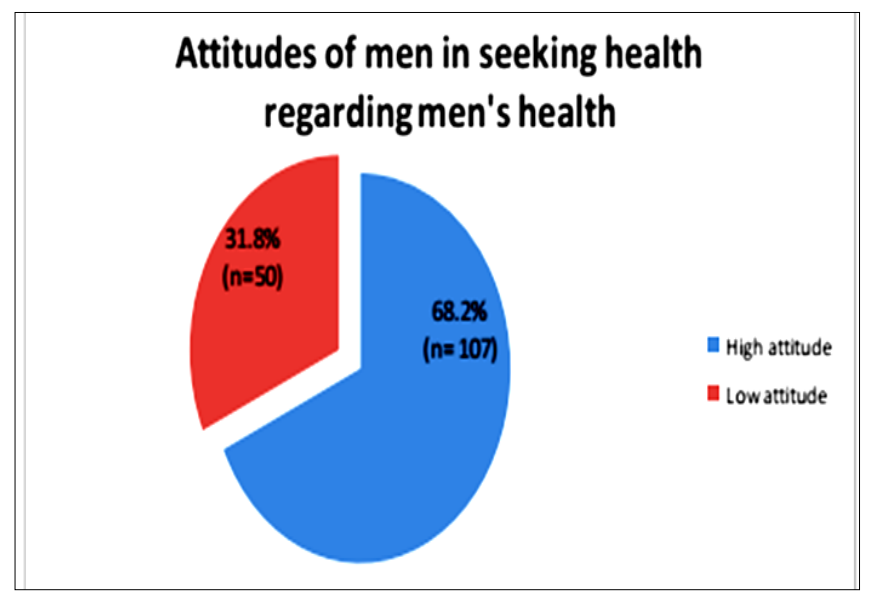

Figure 1: Frequency of attitude of men in seeking health regarding men's health
Figure 2: Frequency of factors affecting men in seeking health regarding men's health

There was no significant value for both demographic data with the attitude of men in seeking for health regarding ME with both $\mathrm{p}$-value $>0.05$. Thus, there was no association between demographic data (age and level of income) with attitude of men in seeking help regarding men's health (Table 2). Table 3.1 and 3.2 shows the total mean score for association between demographic data (age and level of income) with attitudes of men in seeking help ME. For age, the highest mean score were those who aged of 51 and above whose scored $21.83 \quad(S D=2.121)$, followed by those who aged are between 30-40 whose scored $21.21 \quad(S D=2.331)$ and the lowest mean score were from those who were aged 41-50 with the mean of $21.17(S D=2.190)$. Whereas for income, the mean score was the highest for those who aged less than RM 1000 with the mean score of $21.60 \quad(S D=2.044)$, followed by those who earned RM 3001 and above with the mean of $21.48(S D=1.975)$ lastly those who earned RM 1001 -RM 3000 scored $21.17 \quad(S D=2.190)$. Table 3.3 present the mean score for both single and married respondents for attitude of men in seeking help regarding men's health. Respondents who were single have higher mean score which was $21.45(\mathrm{SD}=1.912)$ while married respondents scored slightly lower with the mean of 21.32 
$(\mathrm{SD}=2.324)$.

The result presented in Table 3.3 showed no significant value as the $p$ value $>0.05$. Thus, no association between marital status with attitudes of men in seeking help regarding ME. There is no significant correlation between all three factors (service, cultural and economic) with the attitude of men in seeking help regarding ME as $p$-value for all three factors were more than 0.05 (Table 4.1, 4.2, 4.3).

Table 2

Distribution of frequencies and percentage of attitude of men in seeking health regarding men' shealth $(\mathrm{N}=157)$

\begin{tabular}{|c|c|c|c|}
\hline Statement & Response & Frequency (n) & Percentage (\%) \\
\hline \multirow{2}{*}{$\begin{array}{l}\text { 1.Have you visited a doctor } \\
\text { regarding any men's health } \\
\text { problems? }\end{array}$} & yes & 36 & 22.9 \\
\hline & no & 121 & 77.1 \\
\hline \multirow{2}{*}{$\begin{array}{l}\text { 2. Have you ever spoken to a health } \\
\text { professional about treatment for } \\
\text { difficulties of } \\
\text { getting or keeping an erection? }\end{array}$} & yes & 27 & 17.2 \\
\hline & no & 130 & 82.8 \\
\hline \multirow{2}{*}{$\begin{array}{l}\text { 3. How concerned would you be about } \\
\text { losing your ability to have an erection? }\end{array}$} & Very concerned & 120 & 76.4 \\
\hline & Not concerned at all & 37 & 23.6 \\
\hline \multirow{2}{*}{$\begin{array}{l}\text { 4. How much does prostate cancer } \\
\text { concern you? }\end{array}$} & Very concerned & 136 & 86.6 \\
\hline & Not concerned at all & 21 & 13.4 \\
\hline \multirow{2}{*}{$\begin{array}{l}\text { 5.If you have to spend the rest of your life } \\
\text { with your current prostate health just the } \\
\text { way it is now, how would you feel about } \\
\text { it? }\end{array}$} & Happy & 17 & 10.8 \\
\hline & Unhappy & 140 & 89.2 \\
\hline
\end{tabular}

Table3.1

Association between age and attitudes of men in seeking help in men's health

$(n=157)$

\begin{tabular}{lcccc}
\hline Age & $\mathbf{n}$ & $\operatorname{mean}(\mathrm{SD})$ & F-statistic(df) & Pvalue \\
\hline $30-40$ & 80 & $21.21(2.331)$ & $0.133(2)$ & 0.876 \\
$41-50$ & 41 & $21.17(2.190)$ & & \\
51 and above & 36 & $21.83(2.121)$ & & \\
\hline
\end{tabular}

Table3.2

Association between income and attitudes of men in seeking men's health( $n=157)$

\begin{tabular}{lcccc}
\hline Income & $\mathbf{n}$ & mean(SD) & F-statistic(df) & P-value \\
\hline <RM 1000 & 30 & $21.60(2.044)$ & $0.510(2)$ & 0.601 \\
RM 1001-RM 3000 & 81 & $21.17(2.459)$ & & \\
$>$ RM 3001 & 46 & $21.48(1.975)$ & & \\
& & & & \\
\hline
\end{tabular}

Table3.3

Association between marital status and attitudes of men in seeking men's health

$(\mathrm{AMH})(\mathrm{n}=157)$

\begin{tabular}{llllll}
\hline Variable & $\begin{array}{l}\text { Single } \\
(n=31) \\
\text { Mean (SD) }\end{array}$ & $\begin{array}{l}\text { Married } \\
(\mathrm{n=126)} \\
\text { Mean (SD) }\end{array}$ & $\begin{array}{l}\text { Men diff } \\
(95 \% \mathrm{CI})\end{array}$ & t-statistic(df) & p-value \\
\hline AMH & 21.45 & 21.32 & 0.134 & & \\
& $(1.912)$ & $(2.324)$ & $(-0.757-1.025)$ & $0.297(155)$ & 0.262 \\
\end{tabular}


Table4.1

Correlation between service factor and attitude of men in seeking health regarding men's health $(\mathrm{N}=157)$

\begin{tabular}{lc}
\hline Variable & Service factor \\
\hline Attitude of men in seeking health & $-0.025 \mathrm{a} 0.759 \mathrm{~b}$ \\
\hline $\begin{array}{l}\text { appearson correlation coefficient } \\
\text { bp value }\end{array}$
\end{tabular}

Table4.2

Correlation between attitude of men in seeking health regarding men's health and cultural factor $(\mathrm{N}=157)$

\begin{tabular}{ll}
\hline Variable & Cultural factor \\
\hline Attitude of men in seeking health & $-0.113 \mathrm{a} 0.158 \mathrm{~b}$
\end{tabular}

apearsonm correlation coefficient
bp value
Correlation between attitude of men in seeking health regarding men's health and
Economic factor $(\mathrm{N}=157)$

\begin{tabular}{lc}
\hline Variable & Economic factor \\
\hline Attitude of men in seeking health & $-0.109 \mathrm{a} 0.173 \mathrm{~b}$ \\
\hline $\begin{array}{l}\text { a pearson correlation coefficient } \\
\text { bp value }\end{array}$ &
\end{tabular}

\section{DISCUSSION}

There is no association between age and attitude of men in seeking help regarding $\mathrm{MH}$. There was only a slight different in the mean score between three different age groups which consistent with the result of $p$ value $>0.05$ which can be referred to Table 3.1 where there is no difference between levels of the attitude among men in seeking help regarding $\mathrm{MH}$ between these three age groups. This is consistent with the research done by Gülpinar et al. (2012) in Turkey, ${ }^{10}$ stated that no statistically relevant correlation was proven between treatment-seeking interval and age. However, it is in contrast with research done by Holden et al. (2006) in Australia stated that older man were more likely to discuss about erectile problems with health professionals. ${ }^{1}$ The difference between these two results can be due to different location of the research. As we all know, Australia is a developed country while Turkey, similar like Malaysia is a developing country. Therefore the level of awareness is different between these two countries. Developed countries tend to have higher awareness compared to the developing country causing them to be more open minded in seeking treatment for male reproductive disorders.

There is no association between marital status and attitude of men in seeking health regarding $\mathrm{MH}$ health. This can be referred at Table 3.3, as the $p$ value is 0.262 which is $>0.05$. This is again consistent with research done by Gülpinar et al. $(2012),{ }^{10}$ stated that there is no association between duration of marriage or continued relationship with attitude of seeking for health. Most community has minimal knowledge about prostate health. Although women are usually more particular and more observant of their partner's health, but due to asymptomatic nature of early prostate cancer, a point which the community is singularly uninformed, women's health observation and urgings in this case are not particularly helpful. ${ }^{11}$

There is no association between income and attitude of men in seeking health regarding $\mathrm{MH}$ health. There was only a slight different in the mean score whereby the highest is 21.60 , while the lowest is 21.17. Referring to Table 3.2, the $p$ value $>0.601$ hence it is not statistically proven. Meaning that, levels of their attitude in seeking help regarding $\mathrm{MH}$ health were not accordingly to how much they earned monthly. In contrast, Gülpinar et al.(2012) research reports that low household income had relatively longer help seeking interval. ${ }^{10}$ Additionally, the percentage of men reporting affordability of medical care as another reason not to seek for treatment and it is consistent with results obtained from an earlier cross-sectional study to determine health seeking behavior in Turkey. ${ }^{12}$ The later study also indicates that even when Turkish people decided to seek medical help, they have a tendency to use cheaper practices and therapists recognized by society but not by the state. ${ }^{12}$ There is no correlation between service factor and attitude of men in seeking health regarding $M H$ health. Table 4.1 shows that $p$ value $=0.759$, and $>0.05$ proves that there was no 
IMJM Volume 17 Special Issue No 2

correlation between these two variables. In contrast with research done by Nteta et al. (2010), client perceived quality of services and confidence in the health care provide affect the health care utilization. In addition, preferences to consult a general practitioner of a similar age and gender were underpinned by the desire to minimize embarrassment through discussing sexual concerns with someone they felt was likely to have had similar experiences as themselves. ${ }^{17}$

However, government servant is a working man whereby their working hours may be restricted to attend primary health care services. Working men would not attend health services during working hours. This is why they don't find health as their main priorities, instead they place work as their priority and this is supported by research done by Tong et al. (2011) saying that men have different social priorities and responsibility in life. ${ }^{13}$ Hence, supporting the reason on why there is no correlation between service factor with attitude of men in seeking help regarding ME health.

It is not statistically proven the correlation between cultural factors and attitude of men in seeking help regarding $\mathrm{MH}$ health. Table 4.2 shows that $\mathrm{p}$ value was 0.158 it is proven no correlation between these two variables. It is in contrast with the research done by Galdas et al. (2005), states that general practitioner was not a popular choice for confiding because discomfort associated with communication issues, unfamiliarity, and feeling vulnerable. In addition, illness reduces a man's status in masculinity, shift his power relations with women, raise his self-doubts about his masculinity. ${ }^{15}$ There is no correlation between economic factor and attitude of men in seeking help regarding $\mathrm{MH}$ health. It is not statistically proven with $p$ value $=0.173$ which is $>0.05$ in Table 4.3. In contrast with research done by Nteta et al. (2010), stated that the effect of distance combined with the lack of transportation contributes towards increase cost of visits, hence influences utilization of health services. It is significantly supported by a research done in Pakistan showing that cost has undoubtedly been a major barrier in seeking appropriate health care in Pakistan. ${ }^{16}$

By looking to the findings of this study, men should be educated to seek help regarding $\mathrm{MH}$ health since this issue is important for the reproductive and heredity of human. Men should put aside their ego and feeling of dominant and shameful to ease the process of seeking helps regarding $\mathrm{MH}$ health. Many unhealthy social problems could be risen as a complication of $\mathrm{MH}$ health such as men turn to live in homosexual lifestyle to uncover the lack of themselves or turn to depression or suicide. Islam also teaches us to always find the best solution to problems we are facing and avoid from being despair and ignorant.

\section{CONCLUSION}

$\mathrm{MH}$ health that includes reproductive disorders has always been taken lightly by the male community. Lack of awareness regarding $\mathrm{MH}$ health issue causes men to ignore the importance of health screening. Healthcare provider should have a better understanding about the barriers to $\mathrm{MH}$ help seeking behavior and health services use for reproductive health disorders in order for men to receive best health care. Most of the government servants have high attitude regarding men's health seeking behavior however not everyone practices it. Meaning that, although they have awareness regarding $\mathrm{MH}$ issues they still did not seek for any treatment from the hospital. Service factor should be further improved as it is the main factor that causes low health seeking behavior among government servants. This condition should be improved in order to produce a healthy community for better Ummah since good heredity starts with $\operatorname{good} \mathrm{MH}$.

\section{ACKNOWLEDGEMENT}

The authors are very grateful to the management and participants from JPAM, Kastam, JPJ and Jabatan Bomba dan Keselamatan Kuantan for their kind cooperation during the study period. The technical assistance from lecturers, assistant lecturers, clinical instructors, and staffs in Kulliyyah of Nursing are highly appreciated.

\section{REFERENCES}

1. Holden CA, McLachlan RI, Pitts M, et al. Men in Australia Telephone Survey (MATeS):

predictors of men's help-seeking behaviour for reproductive health disorders. Med J Aust. 2006; 185:418-22.

2. Mulhall J, King R, Glina S, Hvidsten K. Importance of and satisfaction with sex among men and women worldwide: results of the global better sex survey. J Sex Med. 2008; 5:788-95.

3. Lai UC, Wun YT, Luo TC, Pang SM. In a free healthcare system, why do men not consult for lower urinary tract symptoms (LUTS)? AsiaPac Fam Med. 2011; 10:7.

4. Weller D, Pinnock C, Silagy C, Hiller JE, Marshall VR. Prostate cancer testing in SA men: influence of sociodemographic factors, health beliefs and LUTS. Aust N Z J Public Health. 1998; 22:400-2.

5. Smith JA, Braunack-Mayer A, Wittert G. What do we know about men's help-seeking and health service use? Med J Aust. 2006; 184:813. 
6. Tong SF. The decision-making process of primary care doctors in undertaking health check-ups for male patients in Malaysia (Volume 1). 2012. http: // ses.library.usyd.edu.au/ bitstream/2123/8717/1/01SF-Tong2012thesis_HR.pdf. Accessed October 22, 2012.

7. Courtenay WH. Key determinants of the health and the well-being of men and boys. Int J Mens Health. 2003; 2:1-30.

8. Mansfield AK, Addis ME, Mahalik JR. "Why won't he go to the doctor?": the psychology of men's help seeking. Int J Mens Health. 2003; 2:93-109.

9. Courtenay WH. Behavioral factors associated with disease, injury, and death among men: evidence and implications for prevention. $J$ Mens Studies. 2000; 9:81-142.

10. Gülpinar O, Haliloğlu AH, Abdulmajed MI, Bogga MS, Yaman O. Help-seeking interval in erectile dysfunction: analysis of attitudes, beliefs, and factors affecting treatmentseeking interval in Turkish men with previously untreated erectile dysfunction. $J$ Androl. 2012; 33:624-8.

11. Madjar I, Denham J, Rashid P. Do women have a role in early detection of prostate cancer? Lessons from a qualitative study. Aust Fam Physician. 2007; 36:375-7.

12. Hayran 0 , Karavus M, Aksayan S. Help-seeking behavior and self-medication of a population in an urban area in Turkey: cross sectional study. Croat Med J. 2000; 41:327-32.

13. Tong SF, Low WY, Ismail SB, Trevena L, Willcock S. Malaysian primary care doctors' views on men's health: an unresolved jigsaw puzzle. BMC Fam Pract. 2011; 12:29.

14. Galdas PM, Cheater F, Marshall P. Men and health help-seeking behaviour: literature review. J Adv Nurs. 2005; 49:616-23.

15. Charmaz K. Identity dilemmas of chronically ill men. In: Sabo D, Gordon DF, eds. Men's Health and Illness: Gender, Power and the Body. Sage Publications, Thousand Oaks, CA, 1995: 266-91.

16. Shaikh BT, Hatcher J. Health seeking behaviour and health services utilization trends in national health survey of Pakistan: what needs to be done? J Pak Med Assoc. 2007; 57:411-4.

17. Gott M, Hinchliff $S$. How important is sex in later life? The views of older people. Social Science and Medicine. 2003;56(8):1617-1628.

18. Nteta TP, Mokgatle-Nthabu M, Oguntibeju 00. Utilization of the primary health care services in the Tshwane Region of Gauteng Province, South Africa. PloS one. 2010;5(11):e13909. 
